\title{
Finite Element Simulation of Welding Distortion in Dissimilar Joint by Inherent Deformation Method
}

\author{
Mehdi Farajpour ${ }^{1}$, Eslam Ranjbarnodeh ${ }^{2}$ \\ ${ }^{1}$ Islamic Azad University, Department of Engineering, East Tehran Branch, Tehran, Iran. \\ ${ }^{2}$ Amirkabir University of Technology, Faculty of Mining and Metallurgical Engineering, Tehran, Iran.
}

Received: 01 Nov., 2017

Accepted: 23 Mar., 2018

E-mails: mehdi151355@yahoo.com (MF), islam_ranjbar@aut.ac.ir(ER)
This is an Open Access article distributed under the terms of the Creative Commons Attribution Non-Commercial License which permits unrestricted non-commercial use, distribution, and reproduction in any medium provided the original work is properly cited.
Abstract: Fusion welding is widely used to join different parts to each other in various industries. However, welding-induced distortions sometimes cause problems such as misalignment during assembling and impose costs for their removal. Thus, it is imperative to predict and mitigate these problems to improve weldment quality and also reduce fabrication costs. In this study, a dissimilar welded structure was first simulated with 3D solid and shell elements in ANSYS finite element software, and welding-induced deformations were then calculated. Afterwards, the constructed weldment was simulated using an inherent deformation method, and its results were compared with experimental measurements and 3D answers. This comparison showed that it was possible to simulate a dissimilar welded joint using an inherent deformation method in order to reduce the time and cost of modeling even at the expense of a small error.

Key-words: FEM simulation; Inherent deformation; Dissimilar joint; Solid element; Shell element.

\section{Introduction}

Nowadays, fusion welding has become a common practice for joints in several industries thanks to its high construction speed and lower structure weight. However, in spite of its advantages, this type of joint has some drawbacks, including residual stress and structure distortion, especially in dissimilar joints, which result in reduced quality of the structure. Thus, the weld should be designed so as to minimize these drawbacks. In recent decades, researchers have resorted to various numerical and analytical methods for predicting and reducing distortion in structures. Udea measured strains by sectioning perpendicular and parallel to the welded line and using a strain gauge, after which he calculated the stress on the structure by an FEM method [1]. In 1983, he introduced a new method for calculating 3D residual stresses through the measurement of plane strains [2]. Hill successfully measured strain in some points of the structure and then generalized it to the whole structure by Udea's 3D method, thereby predicting the distortion of the structure using a combination of destructive test and finite element analysis [3]. However, at the beginning of the current century, researchers attempted to develop finite element-based methods to measure residual stress and distortion in complicated welded structures without a destructive test. Nevertheless, the simulation of large structures is a time-consuming task. In 2005, Deng introduced the inherent strain concept, described how inherent strains can be measured for a part of the model by elastic-plastic thermal finite element analysis, and calculated the deformations for the whole structure using the results of an elastic analysis [4]. In 2008, he showed how a structure could be simulated in case there was either an initial gap or some initial distortion between plates [5]. Subsequently, Wang used inherent deformation concept to predict the distortion of a large panel from the deck of a ro-ro ship by simulation in Abaqus FE Software Package [6]. In 2014, Wang designed a full panel of a ro-ro ship, and then he predicted and reduced the distortion by an inherent deformation method [7]. In another study, he studied the effect of a different welding sequence on out-of-plane buckling distortion [8]. Similar to Wang, Park studied welding of ship panels by equivalent forces method, which is based on inherent deformation, and designed a welding sequence that minimized distortion for a ship [9]. In 2015, Rezaei et al. studied a large panel by inherent deformation theory and proposed a welding sequence appropriate to minimize distortion [10].

According to the studies, simulation by inherent deformation is a new method that needs further studies. In addition, to the best knowledge of the authors, this method has 
not been used for dissimilar joints yet. Therefore, in the present study, a dissimilar sample was made of low carbon steel and stainless steel and was subsequently simulated with 3D method in ANSYS finite element software package. Then, the inherent deformations were measured, the built sample was simulated by an inherent deformation method, and the findings were compared with empirical results. The comparison showed that the method could predict the distortion for dissimilar joints with a good precision and that at the same time it considerably reduced the analysis time.

\section{Inherent Deformation Theory}

Given the uniform movement of the heat source in a certain distance from the edge of the plate (except for the start and end points), the strains generated by heat application are expected to be uniform along the welded line because temperature field created for these points will be uniform. The application of local heat creates different types of elastic, plastic, thermal, and creep strains in the plate as well as in the welded zone. The elastic part of these strains is reversible and is removed after cooling; however, other parts of the strain remain and their sum is defined as the inherent strain [11], which is expressed by Equation 1:

$$
\varepsilon_{\text {total }}-\varepsilon_{\text {elastic }}=\varepsilon_{\text {thermal }}+\varepsilon_{\text {creep }}+\varepsilon_{\text {plastic }}=\varepsilon_{\text {inherent }}
$$

In a welded structure, the creep and thermal strains are negligible and can be ignored [6]. So, in welding, the amount of inherent strain in each direction is equal to the amount of plastic strain in that direction, and Equation 1 is rephrased as Equation 2:

$$
\varepsilon_{\text {total }}-\varepsilon_{\text {elastic }}=\varepsilon_{\text {plastic }}=\varepsilon_{\text {inherent }}
$$

These amounts can be calculated for a small part of the structure by its simulation with the appropriate welded line, which can be fed into an elastic model designed from the complete structure. Then, its distortion can be calculated with elastic analysis [12]. However, it is difficult to apply inherent strains on the model. So, it is assumed that there is an inherent amount of deformation for each section perpendicular to the welded line. It is possible to calculate inherent deformation and apply it in the model instead of applying the distribution of inherent strains in the elastic model. The amounts of inherent deformations can be derived by integrating inherent strains over their distribution zone according to Equations 3-6 [6]:

$$
\begin{aligned}
& \delta_{z}=\int \varepsilon_{z}^{*} \cdot d A \\
& \delta_{x}=\int \varepsilon_{x}^{*} \cdot d A \\
& \theta_{z}=\int \varepsilon_{z}^{*} \cdot\left(y-\frac{h}{2}\right) \cdot d A \\
& \theta_{x}=\int \varepsilon_{x}^{*} \cdot\left(y-\frac{h}{2}\right) \cdot d A
\end{aligned}
$$

where $Z$ is defined along welded line, $X$ is defined perpendicular to welded line, and $Y$ is defined along thickness. $\delta_{z}, \delta_{x}, \theta_{z}$, and $\theta_{x}$ are longitudinal shrinkage, transverse shrinkage, longitudinal buckling, and transverse buckling, respectively. $\varepsilon_{z}^{*}$ and $\varepsilon_{x}^{*}$ are longitudinal and transverse inherent strains, respectively, and $h$ shows thickness. $A$ is the cross section perpendicular to the welded line.

\section{Empirical Model}

To study inherent deformation for a dissimilar joint using a numerical method, first two $225 \mathrm{~mm} \times 80 \mathrm{~mm} \times 2 \mathrm{~mm}$ plates were made of carbon steel and stainless steel with CK4 and AISI409 grades, respectively. The welding setup is shown in Figure 1. Gas tungsten arc welding (GTAW) is also an arc welding process that uses a non-consumable tungsten electrode to produce the weld. The distance of workpiece electrode was $1 \mathrm{~mm}$ for all the welded samples. 


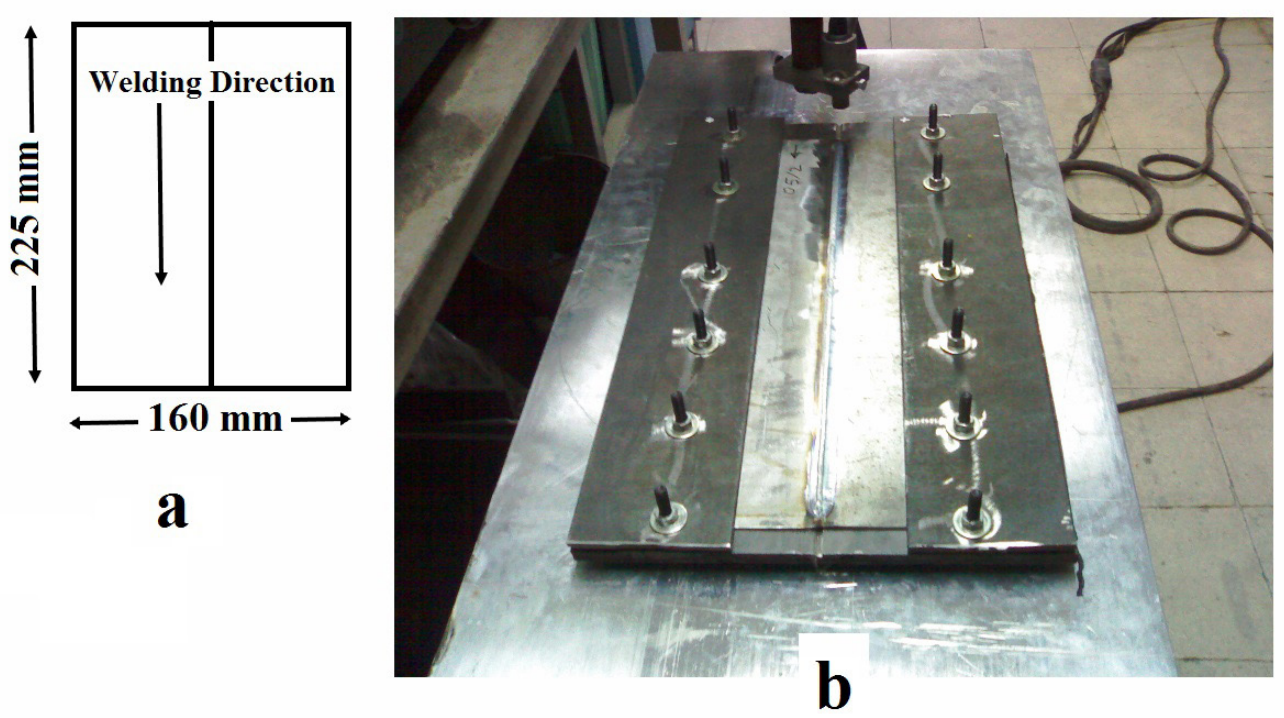

Figure 1. The welding arrangement: (a) Dimensions and (b) Welding operation.

The assembly was performed with the welding current of $120 \mathrm{~A}$ (DCEN), the voltage of $13 \mathrm{~V}$, and the welding rate of $3.56 \mathrm{~mm} / \mathrm{s}$. In this joint, the movement of two parallel edges of the welded line was restrained vertically. Figure 2 shows the model built after welding operation. The distortion induced by welding was measured using a height Vernier caliper.

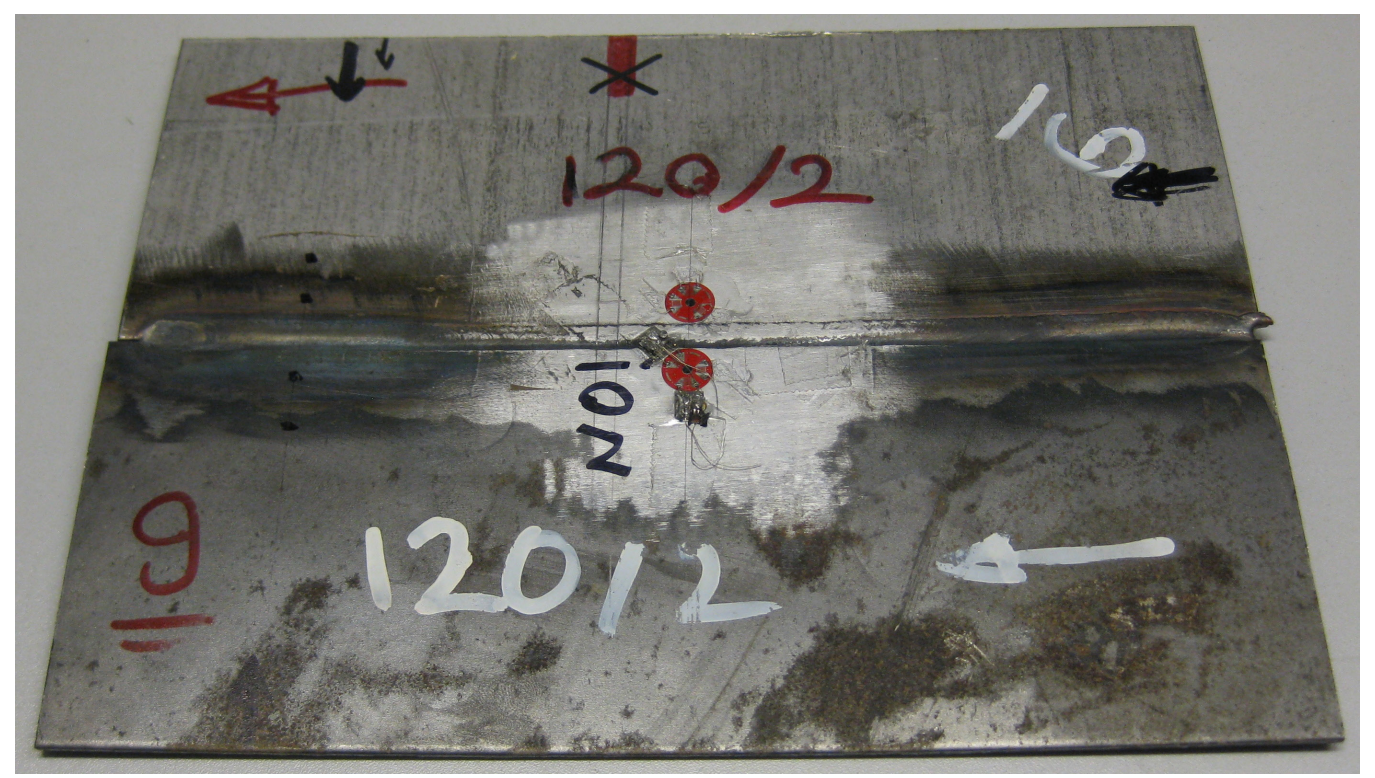

Figure 2. The built model.

\subsection{Three-dimensional simulation}

The geometric model built for the sample described in Section 3 is depicted in Figure 3. In this model, two plates of steel, one mild and the other stainless, were butted against each other. To simulate a welded structure, all parts should be first modeled and joined to one another. In this study, the model was built as an integrated system to avoid using joining elements and to reduce the volume and time of calculations. 


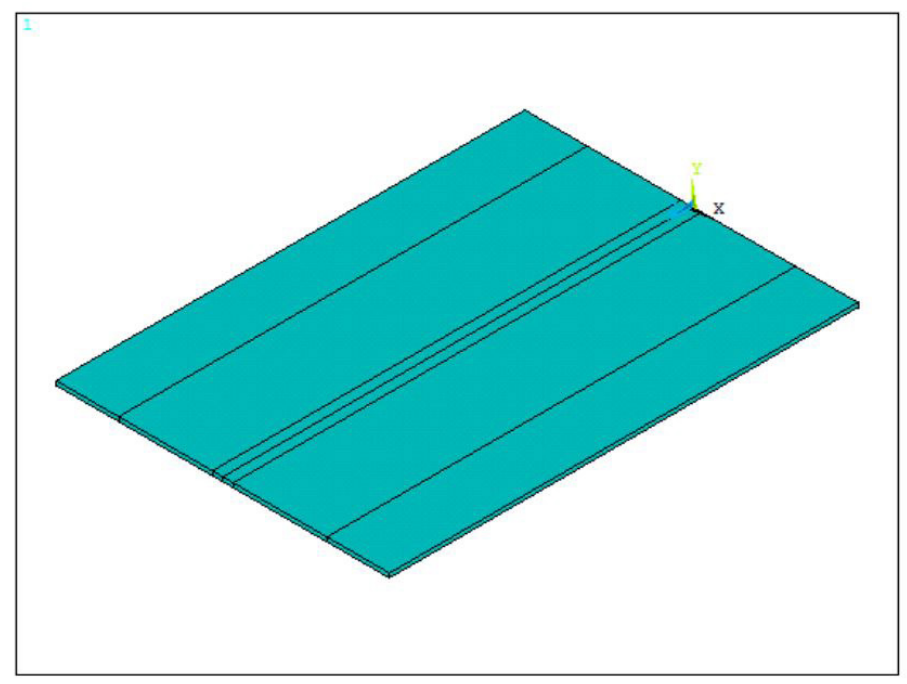

Figure 3. The geometrical sample built in ANSYS software.

After building the model, the thermal and thermodynamic properties of the materials should be defined. The metals applied in the present study were mild and stainless steels (grades CK4 and AISI409), the material properties of which are presented in Tables 1 and 2, respectively. The built model should have an appropriate meshing so that thermal analysis can provide precise temperature field and thermal gradient. To this end, the meshes should be fine enough in the proximity of the thermal source and in the part where weld pool is located, and the elements should be larger in further parts where the thermal gradient is lower with lower sensitivity. In this simulation, Solid 278-8 nodes element was used for the meshing of the thermal model, and Solid 45-8 nodes element was used for the meshing of the mechanical model. The elements had identical dimensions in both parts, and only element type differed according to thermal or structural analysis. Mesh sensitivity analysis was performed, and the results showed that four elements were enough through thickness.

Table 1. Thermal and mechanical properties of mild steel.

\begin{tabular}{cccccccc}
\hline $\begin{array}{c}\text { Temperature } \\
\left({ }^{\circ} \mathrm{C}\right)\end{array}$ & $\begin{array}{c}\text { Density } \\
\left(\mathbf{k g} / \mathbf{m}^{\mathbf{3}}\right)\end{array}$ & $\begin{array}{c}\text { Specific } \\
\text { heat } \\
(\mathbf{J} / \mathbf{k g} \cdot \mathbf{K})\end{array}$ & $\begin{array}{c}\text { Conduction } \\
\text { coefficient } \\
(\mathbf{W} / \mathbf{m} \cdot \mathbf{K})\end{array}$ & $\begin{array}{c}\text { Elasticity } \\
\text { coefficient }\end{array}$ & $\begin{array}{c}\text { Poisson } \\
\text { ratio }\end{array}$ & $\begin{array}{c}\text { Thermal } \\
\text { expansion } \\
\left(\boldsymbol{\circ}^{-1}\right)\end{array}$ & $\begin{array}{c}\text { Yield stress } \\
(\mathbf{P a})\end{array}$ \\
20 & 7800 & 425 & 51.5 & $2.00 \mathrm{E}+11$ & 0.3 & $1.17 \mathrm{E}-05$ & $2.90 \mathrm{E}+08$ \\
675 & 7800 & 846 & 45 & - & 0.3 & - & - \\
700 & 7800 & 1139 & 40 & - & 0.3 & - & - \\
730 & 7800 & 1384 & 35 & - & 0.3 & - & - \\
750 & 7800 & 1191 & 29.7 & - & 0.3 & - & - \\
1000 & 7800 & 799 & 29.7 & - & 0.3 & - & - \\
1500 & 7800 & 400 & 29.7 & $5.00 \mathrm{E}+09$ & 0.3 & - & $5.00 \mathrm{E}+06$ \\
\hline
\end{tabular}

Table 2. Thermal and mechanical properties of stainless steel.

\begin{tabular}{cccccccc}
\hline $\begin{array}{c}\text { Temperature } \\
\left({ }^{\circ} \mathrm{C}\right)\end{array}$ & $\begin{array}{c}\text { Density } \\
\left(\mathbf{k g} / \mathbf{m}^{3}\right)\end{array}$ & $\begin{array}{c}\text { Specific } \\
\text { heat } \\
(\mathbf{J} / \mathbf{k g} \cdot \mathbf{K})\end{array}$ & $\begin{array}{c}\text { Conduction } \\
\text { coefficient } \\
(\mathbf{W} / \mathbf{m} \cdot \mathbf{K})\end{array}$ & $\begin{array}{c}\text { Elasticity } \\
\text { coefficient }\end{array}$ & $\begin{array}{c}\text { Poisson } \\
\text { ratio }\end{array}$ & $\begin{array}{c}\text { Thermal } \\
\text { expansion } \\
\left.\left({ }^{\circ}\right)^{-1}\right)\end{array}$ & $\begin{array}{c}\text { Yield stress } \\
(\mathbf{P a})\end{array}$ \\
20 & 7700 & 460 & 25 & $2.20 \mathrm{E}+11$ & 0.3 & $1.20 \mathrm{E}-05$ & $2.05 \mathrm{E}+08$ \\
500 & 7700 & - & 30 & - & 0.3 & - & $5.00 \mathrm{E}+06$ \\
1400 & 7700 & - & 30 & $5.00 \mathrm{E}+0.9$ & 0.3 & - & - \\
2000 & 7700 & - & 90 & - & - & & \\
\hline
\end{tabular}


Figure 4 presents the meshing of the designed model. The smallest elements were $1 \mathrm{~mm}$ near the welded line, and the largest ones were $30 \mathrm{~mm}$ on the edge. At the next step, SURF-152 surface four-nodal elements were used to apply source thermal flow. This is worth noting that the mesh sensitivity analysis was done to verify that the result does not change significantly with different meshing. The model for the analysis of solid element was built with 9000 elements and 9500 nodes. As is evident in Figure 3, the base metal and the filler metal were designed simultaneously in this modeling, but obviously, there was no filling element at a certain point before the thermal source was reached. Therefore, the stiffness matrix of these elements should be multiplied by a large reducing factor to have all irrelevant elements deactivated, which is done by the element birth and death technique in ANSYS. In this technique, all elements are deactivated at the beginning of the analysis, and the relevant element is activated when thermal source reaches the desired point [11]. Then, boundary conditions are applied. The boundary condition applied in this simulation included the application of the convective heat transfer for the surfaces exposed to the fresh air. The convective heat transfer equation (Equation 7) is as follows:

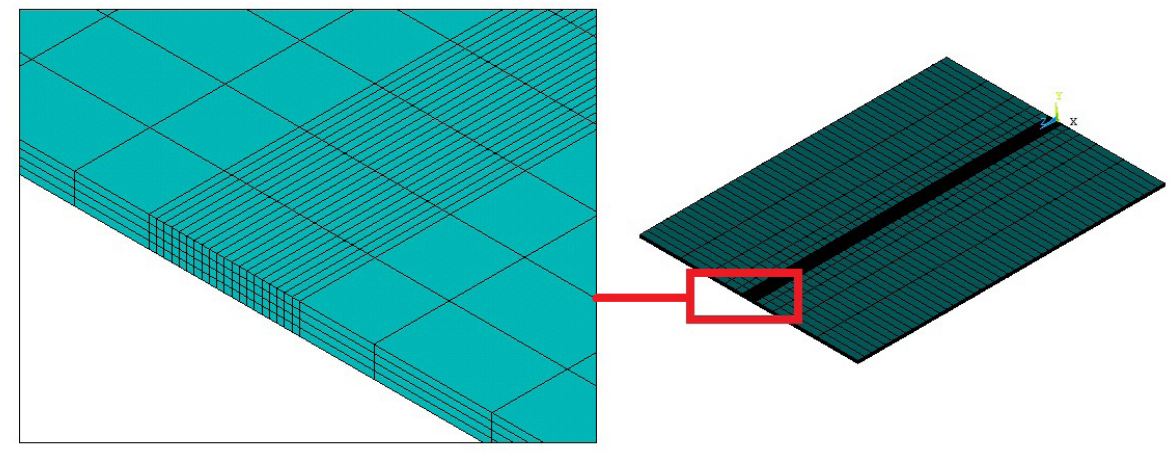

Figure 4. Meshing of 3D model.

$$
q=h \times A\left(T-t_{\infty}\right)
$$

where $h$ is conductive heat transfer coefficient (assumed to be $15 \mathrm{~W} / \mathrm{m}^{2} \mathrm{c}$ under the environmental conditions of the experiment), $A$ is the area, and $t_{\infty}$ is the ambient temperature. The convection coefficient was assumed equal to $800 \mathrm{~W} / \mathrm{m}^{2} \mathrm{~K}$ for the surfaces that were in contact with the backing plate [10]. Then, thermal source was applied to model through developing the macro in ANSYS Software Package. GTAW welding thermal source was modeled with Gaussian normal distribution [3,11,13], which is shown in Equation 8:

$$
q(x)=\frac{3 \cdot Q_{a r c}}{\pi r_{a}^{2}} \cdot \exp \left(\frac{r(x)}{r_{a}}\right)
$$

where $r_{a}$ is the radius of Gaussian thermal source that depends on torch geometry. In the present study, $r_{a}$ was assumed to be $1.5 \mathrm{~mm}$. Also, $r(x)$ is the distance from the center of the thermal source, and $Q_{\text {arc }}$ is the temperature of the thermal heat obtained by Equation 9:

$$
Q=\eta \cdot I . V
$$

where $I$ is the current, $V$ is the voltage, and $\eta$ is the thermal source efficiency assumed to be 0.6. Finally, models with $8300,9500,10050$, and 10700 elements were designed and analyzed thermally to study the sensitivity of the mesh.

After thermal analysis, the mechanical model was developed with changing thermal elements to Solid 45 mechanical elements. Then, the properties were defined for the model according to what was mentioned in previous sections. Next, boundary conditions were applied according to Figure 5. 
Directions shown in Figure 5 express the freedom degree closed in that direction. Next, the temperature field was applied to the model and was analyzed as a transient problem. In total, the thermal and mechanical analyses lasted 40 minutes. It is worthwhile to note that the computer used for analysis was Dual core $3.40 \mathrm{GHz}$, $3.39 \mathrm{GHz}$ with 4GB RAM.

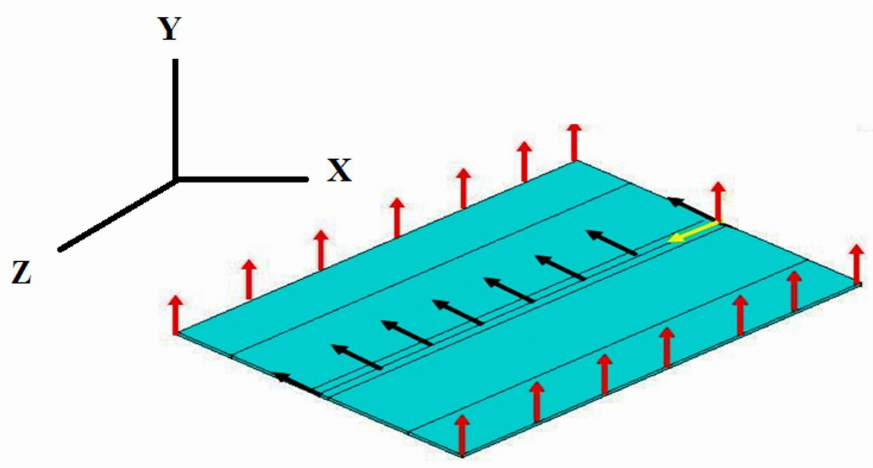

Figure 5. Boundary conditions.

\subsection{Simulation using inherent deformation method}

To estimate inherent deformations, a smaller part of the model can be simulated with solid elements in order to estimate the quantities. However, in this work, since the whole model was simulated using a 3D method as described in the previous section, that model was used for estimating inherent deformations, too. To obtain inherent deformation zone, the distribution of longitudinal and transverse plastic strains was considered and the one having larger amount of deformation was selected as the zone of inherent strain around weld pool.

As is evident in Figure 6, the distribution zone of longitudinal strain is larger than transverse strain in this case, so the former zone was selected. Then, the plastic strain of each element was calculated on the selected area in longitudinal direction $\mathrm{Z}$ and transverse direction $\mathrm{X}$. Next, the inherent deformations were estimated using Equations 3-6 on the selected area. If welding is carried out in multiple steps, the deformations should

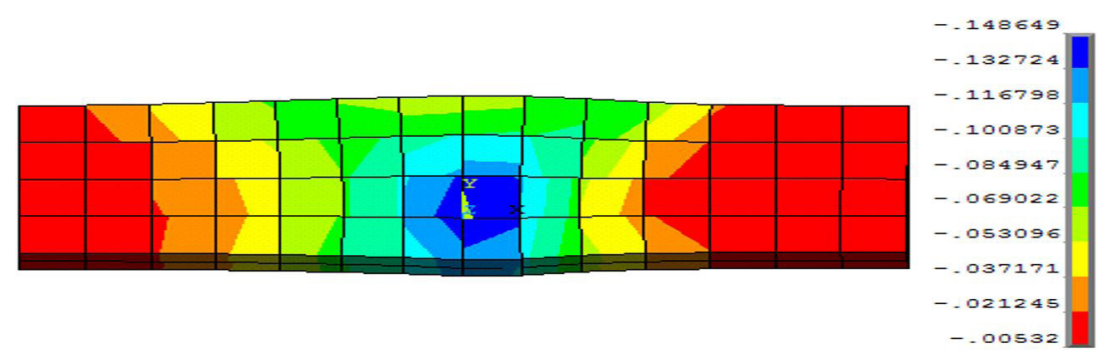

(a)

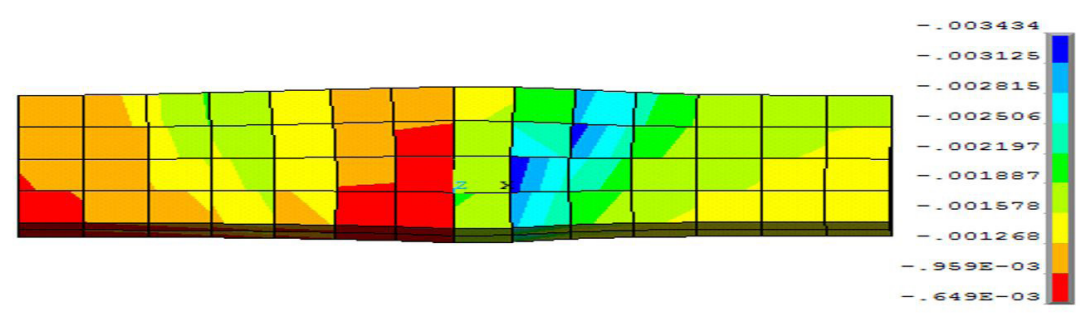

(b)

Figure 6. The distribution of plastic strains: (a) Longitudinal and (b) Transverse strain in Z= $100 \mathrm{~mm}$. 
be separately calculated for each step and applied to the elastic model step-by-step. Furthermore, if there are different welding arrangements, this procedure can be applied for each one individually and applied to the elastic model step-by-step. After the inherent deformations were estimated, the built model was simulated using shell element. The solution time is exponentially decreased for this element since it has fewer nodes, even though this approach can be a source of error. The models designed with this element type are solved with Mind and Lin's theory [14] of plate and sell because the algorithm for this type of element in ANSYS finite element software is based on the mentioned theory.

Figure 7 depicts the built model and the relevant meshing. In this section, the meshing should be similar to the meshing in 3D part. Shell elements 181-4 nodes were used for element arrangement of the model in this part. The boundary conditions were applied to the model similar to the previous case according to Figure 5, and the inherent deformations estimated in accordance with Figure 8 were applied to the finite element model.

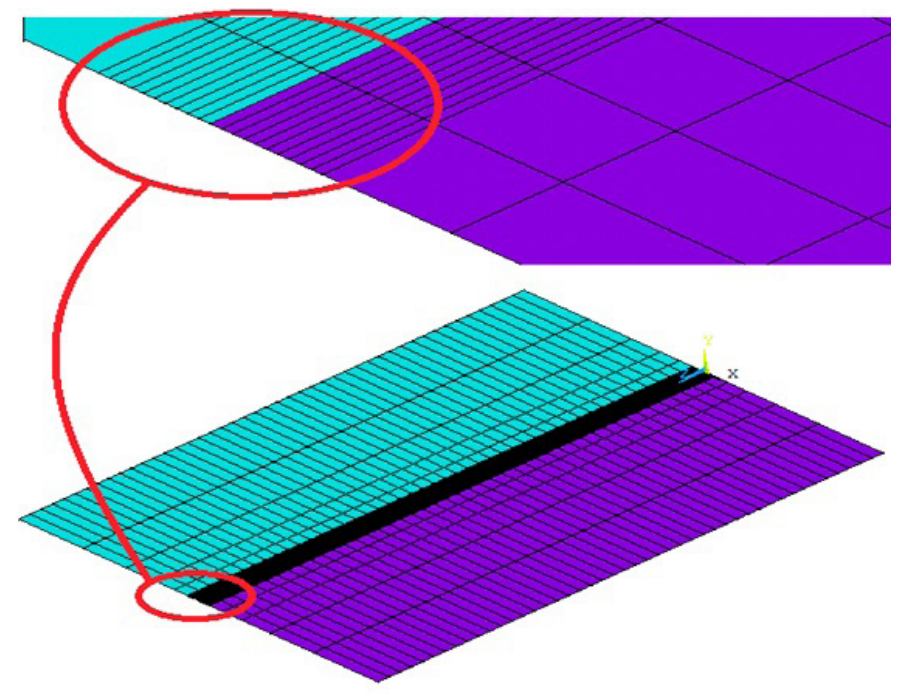

Figure 7. The built model and meshing using shell element.

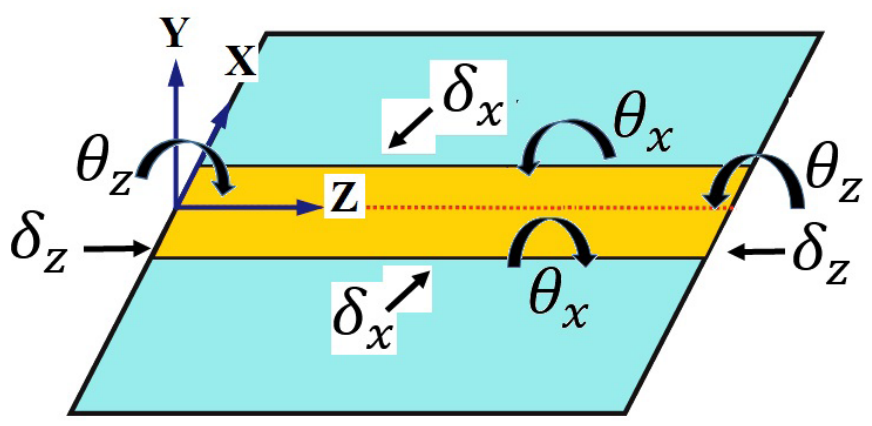

Figure 8. The application of inherent deformations.

In this part of problem solving, the load was aggregately applied to the nodes, and the problem was solved statically rather than by transient analysis. The conversion of analysis type from transient to static considerably decreased the calculations. At this step, total problem-solving time was cut by five minutes. Next, to study the mechanism of distortion and to answer the question which inherent deformation was more effective on a certain distortion, only longitudinal shrinkage was considered, other deformations were neglected, and the elastic analysis was repeated. In the next step, just transverse distortion and buckling around Z-axis were applied, and the elastic analysis was carried out. At the third step, just buckling around Z-axis was applied. 


\section{Results and Discussion}

The distortion at the end of the welded line was calculated to be $5.85 \mathrm{~mm}$ in the vertical direction (see Figure 2). Figure 9 shows the weld pool obtained by metallography, according to which the penetration depth was $4.43 \mathrm{~mm}$.

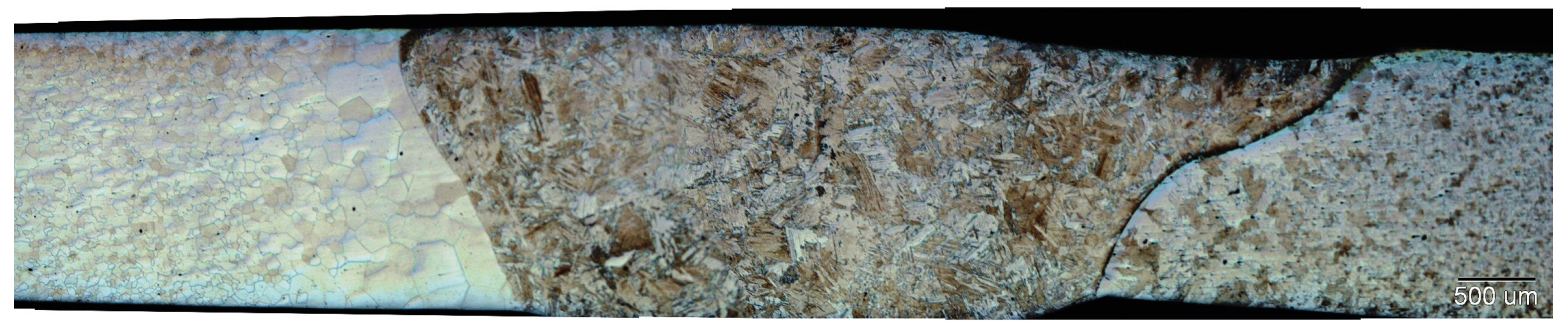

Figure 9. Weld pool obtained from metallography.

Figure 10 depicts maximum temperature in the weld pool in models with different elements. As is evident, when the number of elements is over 9000 , the maximum temperature is almost constantly equal to $2900 \mathrm{~K}$ with no considerable variation, whereas the maximum temperature obtained for models with fewer elements exhibits approximately $15 \%$ error rate. It seems that the 9000 -element model is ideal for thermal and mechanical analysis so that the numerical answers will be independent of meshing.

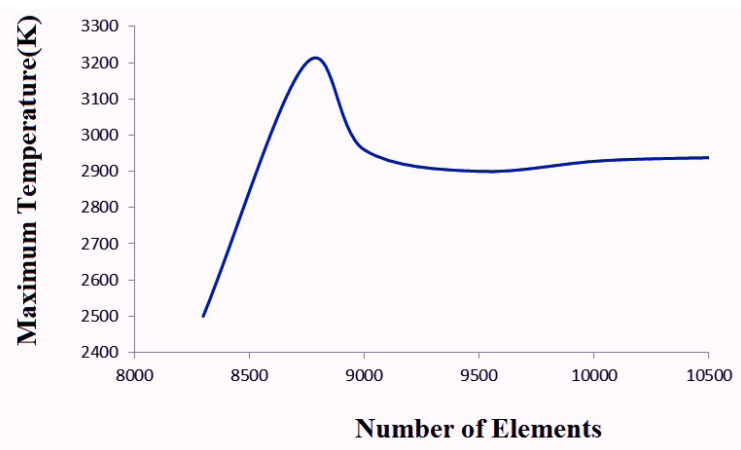

Figure 10. Mesh sensitivity graph (maximum temperature for different numbers of elements).

Figure 11 shows the simulated weld pool and the weld pool obtained from the metallographic experiment. Accordingly, the simulated weld pool width is about $5 \mathrm{~mm}$, showing $11 \%$ difference with the real one, indicating an error rate negligible for thermal simulation. Now, if the distortion predicted by mechanical analysis is shown to be correct, then the correctness of thermal and mechanical simulations can be assured, and there will be no need for mechanical mesh sensitivity analysis. Otherwise, the thermal simulation should be repeated with finer elements.

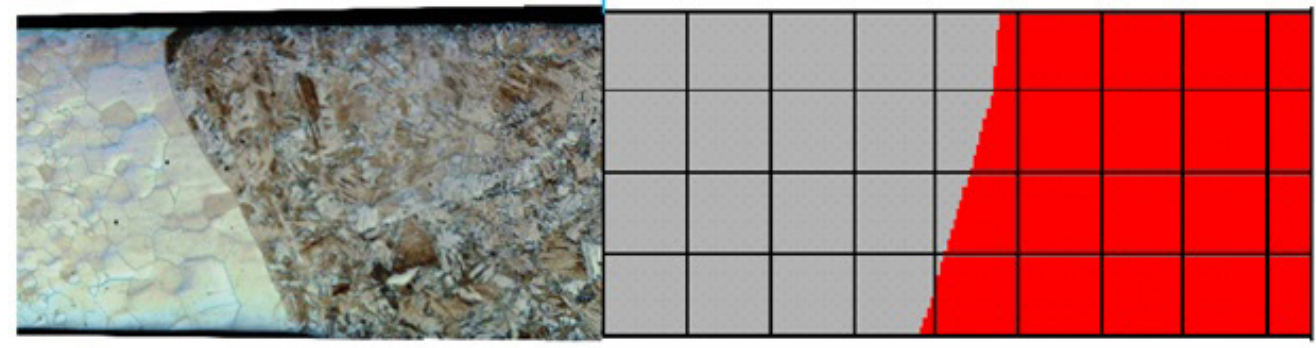

$1 \mathrm{~mm}$

Figure 11. Comparison between experimental and simulated weld pool shapes. 
Figure 12 presents the vertical displacement contour for the simulated model, according to which the highest distortion was $5.57 \mathrm{~mm}$, which was observed at the end of the welded line. It showed that the error rate of mechanical analysis was less than $6 \%$. Thus, the thermal and mechanical analyses were found to be valid.

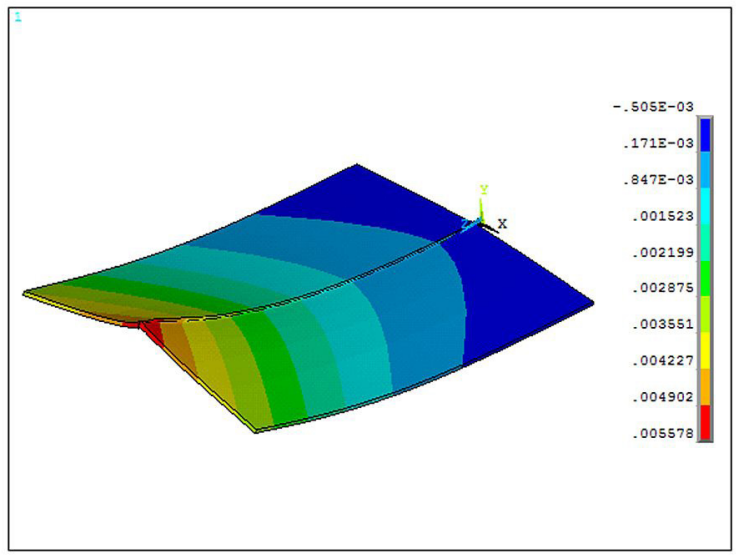

Figure 12. Vertical shift contour of 3D model.

Figure 13 indicates the thermal cycle diagram for different points and along the welded line. It reveals that temperature-time variations are uniform at all points except for the extreme points. So, inherent deformations for the intermediate points with the same temperature history can be expected to be almost equal.

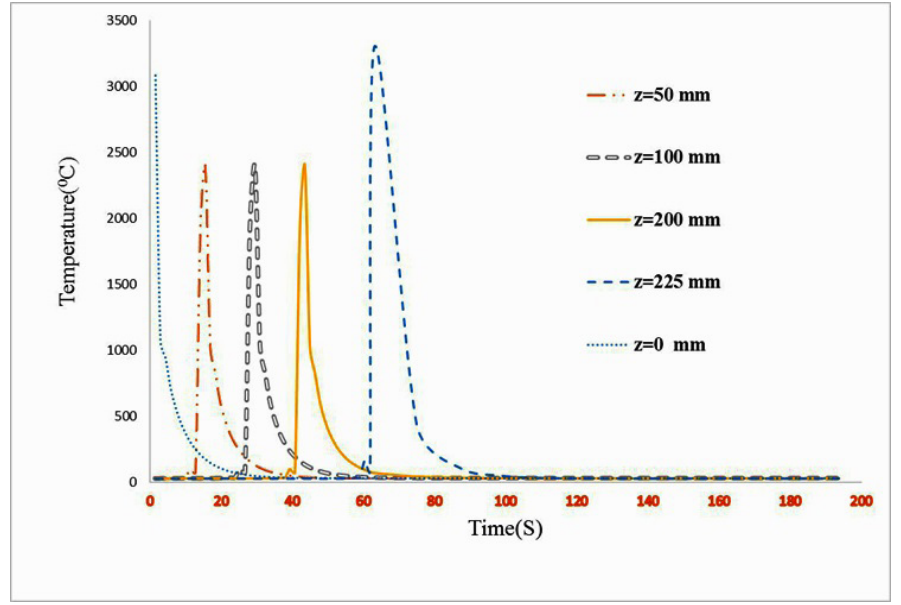

Figure 13. Thermal cycle diagram along the welded line.

Figures 14-16 depict longitudinal, transverse, and radial inherent distortions of the simulated model and along the welded line. Obviously, these values are almost uniform along the welded line as well as in a distance of about five times as high as the thickness of the plates. So, these values can be calculated for an intermediate cross-section and can be subsequently applied to the whole elastic model.

In this work, these values were calculated for an intermediate cross-section ( $z=100 \mathrm{~mm}$ ) as shown in Table 3 and were applied to the elastic model.

Figure 17 shows the distortion along the vertical direction for the elastic model, according to which the maximum distortion is $5 \mathrm{~mm}$, showing $17 \%$ difference with the real model. This error rate is acceptable for the mechanical analysis. Therefore, it can be concluded that the inherent deformation method is appropriate for 


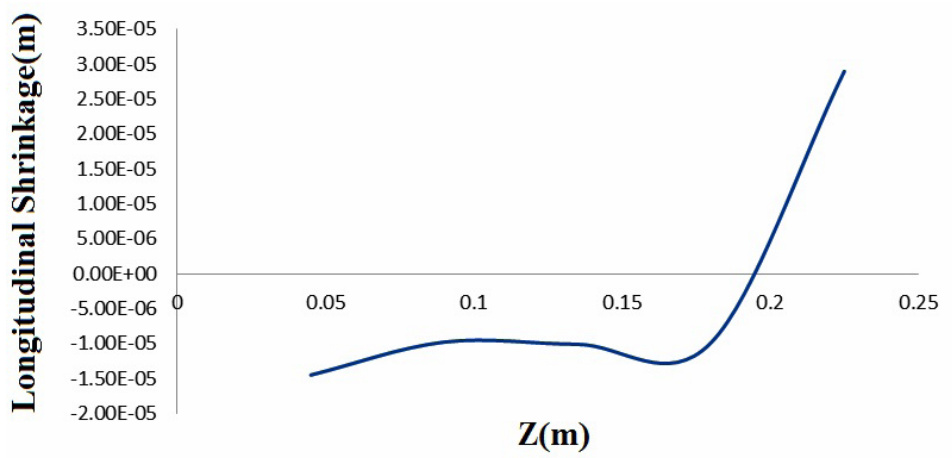

Figure 14. Longitudinal shrinkage along welded line.

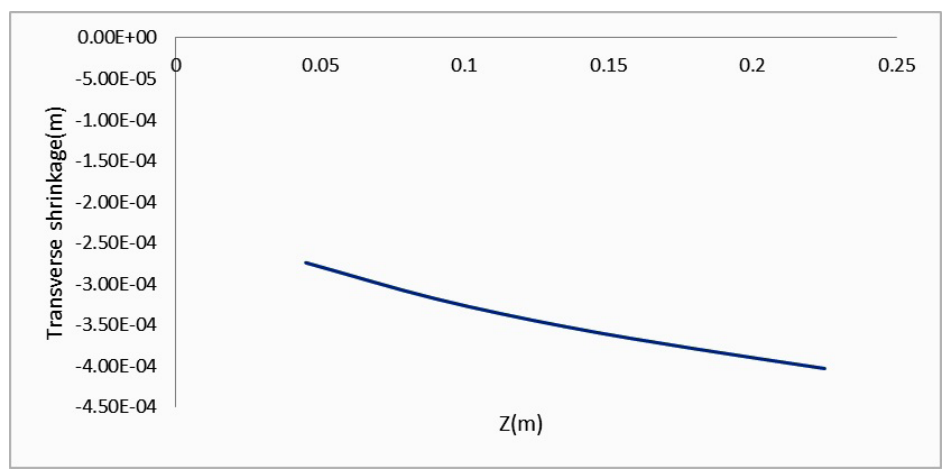

Figure 15. Transverse shrinkage along welded line.

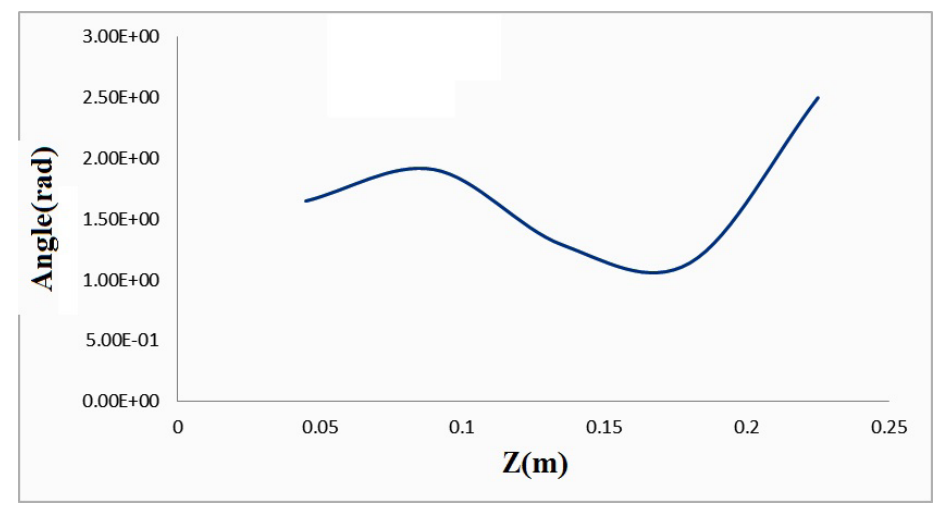

Figure 16. Buckling around welded line.

Table 3. Calculated inherent deformations.

\begin{tabular}{ccc}
\hline $\begin{array}{c}\theta_{x} \text { inherent buckling in transverse } \\
\text { direction (rad) }\end{array}$ & $\delta_{x}$ transverse inherent deformation \\
$(\mathbf{m m})$ & -0.3 & $\begin{array}{c}\delta_{z} \text { longitudinal inherent } \\
\text { deformation }(\mathbf{m m})\end{array}$ \\
-0.1 & & -0.01 \\
\hline
\end{tabular}




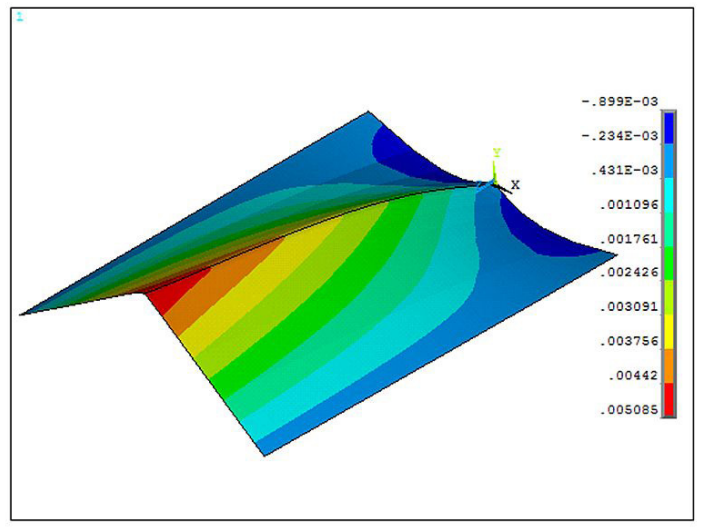

Figure 17. Vertical distortion contour for elastic model [m].

dissimilar weld joints and that it can be used to obtain precise answers. At the next step, to study the distortion mechanism and the deformation having the greatest effect on distortion, the deformations were eliminated one by one, and the problem was analyzed in the presence of other distortions.

Figure 18 displays the displacement contour along the vertical direction for the case in which the tendon force was eliminated longitudinally and only transverse deformations as well as buckling around Z-axis were applied. The comparison of Figure 18 and Figure 19 reveals that the shift does not change in vertical direction. Thus, it can be concluded that the inherent deformation along the welded line has a negligible impact on the distortion along the vertical direction.

Figure 19 depicts the shift contour in the vertical direction with the application of just tendon force. It indicates that the inherent deformation along the vertical direction has a slight impact on the misalignment generated along

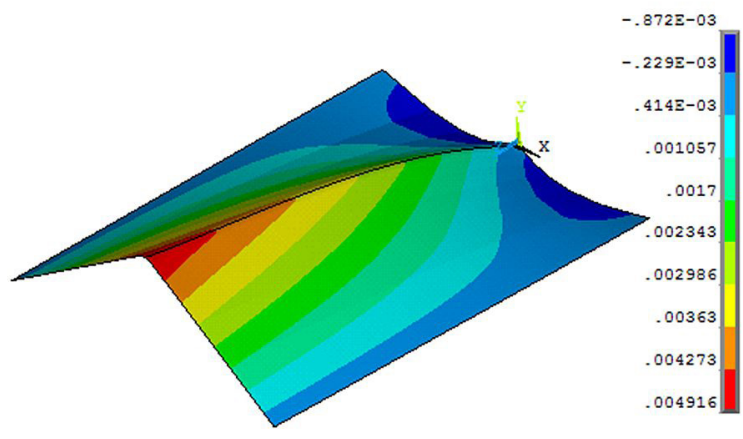

Figure 18. Vertical shift without the application of longitudinal tendon force [m].

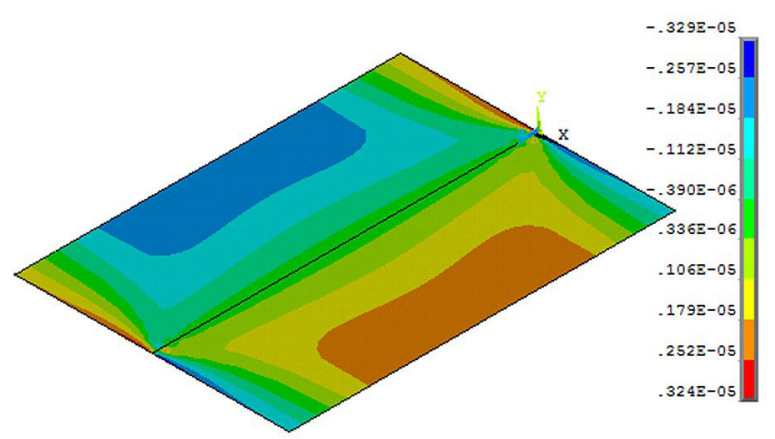

Figure 19. Vertical shift contour with the application of only tendon force [m]. 
the vertical direction. When only buckling around Z-axis is applied, the distortion generation along the vertical direction will again change slightly. Therefore, it can be inferred that the buckling around Z-axis is the main inherent deformation influencing the distortion along the vertical direction. This inherent deformation is obtained by the integration of the transverse inherent strains. So, it can be said that transverse strains have the main effect on the distortion along the vertical direction, as well as on the buckling around Z-axis.

\section{Conclusion}

In this work, using empirical experiments and numerical simulation, it was tried to find a new method to simulate the welded structures with dissimilar joints by software. The conventional simulation methods use solid 9-node elements, which needs a large memory as well as a time-consuming analysis. Nevertheless, simulation with the inherent deformations uses 4-node shell elements, reducing the required memory and the time needed for analysis. The following results were drawn from the present study:

- The use of shell elements and inherent deformations is an appropriate method for predicting and reducing distortions in dissimilar joints, which has acceptable precision;

- The experimental weld pool width is $5.6 \mathrm{~mm}$ while the thermal simulation result is about $5 \mathrm{~mm}$, showing $11 \%$ error rate for the thermal analysis, which is reasonable for the thermal analysis;

- Empirical results show that the distortion is $5.85 \mathrm{~mm}$ in the vertical direction in the built model, whereas the numerical analysis with the inherent deformation method shows on average $5 \mathrm{~mm}$ distortion, indicating $17 \%$ error rate in the elastic analysis;

- Transverse shrinkages and transverse buckling create in-plane distortion and shift in the vertical direction;

- Longitudinal distortion has a negligible effect on distortion in the vertical direction and has the strongest effect on out-of-plane distortion;

- Inherent deformation method reduces analysis time by $70 \%$, is appropriate for large, complex structures, and we can use it for other thicknesses as a future work.

\section{Acknowledgements}

This research was supported by Islamic Azad University, East Tehran branch.

\section{References}

[1] Udea Y, Fukuda K, Nacacho K. A new measuring method of residual stress with the aid of finite element method and reliability of estimated values. Transaction of JWRI. 1979;4(2):499-507.

[2] Udea Y, Fukuda K, Fukuda M. A measuring theory of three dimensional residual stresses in long welded joints. Transaction of JWRI. 1983;12(1):845-853.

[3] Hill M, Nelson D. The inherent strain method for residual stress determination and its application to long welded joint. USA: Mechanical Engineering Department, Stanford University; 2002. $250 \mathrm{p}$.

[4] Liang W, Deng D, Sone S, Murakawa H. Prediction of welding distortion by elastic finite element analysis using inherent deformation estimated through inverse analysis. Welding in the World. 2005;49(11):30-39. http://dx.doi.org/10.1007/ BF03266500.

[5] Deng D, Murakawa H. FEM prediction of buckling distortion induced by welding in thin plate panel structure. Computational Materials Science. 2008;43(4):591-607. http://dx.doi.org/10.1016/j. commatsci.2008.01.003.

[6] Wang J, Rashed S, Murakawa H, Luo Y. Numerical prediction and mitigation of out of plane welding distortion in ship panel structure by elastic fe analysis. Marine Structures. 2013;34(1):135155. http://dx.doi.org/10.1016/j.marstruc.2013.09.003.

[7] Wang J, Rashed S, Murakawa H. Mechanism investigation of welding induced buckling using inherent deformation method. Thin-walled Structures. 2014;80(1):103-119. http://dx.doi. org/10.1016/j.tws.2014.03.003.

[8] Wang J, Ma N, Murakawa H. An efficient FE computation for predicting welding induced buckling in production of ship panel structure. Marine Structures. 2015;80(1):20-52. http://dx.doi. org/10.1016/j.marstruc.2014.12.007.

[9] Park J-U, An GB. Effect of welding sequence to minimize fillet welding distortion in a ship's small component fabrication using joint rigidity method. Proceedings of the Institution of Mechanical Engineers. Part B, Journal of Engineering Manufacture. 2015;230(4):643-653. http://dx.doi.org/10.1177/0954405415589716.

[10] Rezaei A, Ranjbarnodeh I, Iranmanesh M. Finite element prediction of distortion and the impact of sequence in large weld structure by inherent deformation method. Iranian Journal of Welding Sciences \& Technology. 2015;1(1):76-90 [in Persian]

[11] Deng D, Murakawa H, Liang W. Numerical simulation of welding distortion in large structure. Computer Methods in Applied 
Mechanics and Engineering. 2007;196(45):4613-4627. http:// dx.doi.org/10.1016/j.cma.2007.05.023.

[12] Rui W, Sherif R, Hisashi S. Study on welding inherent deformation in welded structural material. Transaction of JWRI. 2008;37(1):9199.
[13] Wang J, Rashed S, Murakawa H. Investigation Of Buckling Deformation Of Thin Plate Welded Structure. Transaction of JWRI. 2011:41(1):125-131.

[14] ANSYS. Ansys Mechanical APDL Operation Guide Release. Canonsburg: ANSYS, Inc; 2013. 